\title{
Evaluating Information Obtained from Diagnosis of Pregnancy Status of Beef Herds
}

Robert L. Larson, DVM, PhD, ACT, ACVPM-Epi (Corresponding Author)

Department of Clinical Sciences

College of Veterinary Medicine

Kansas State University

1800 Denison Ave.

Manhattan, KS 66506

(785)532-4257

RLarson@vet.ksu.edu

Brad J. White, DVM, MS

Department of Clinical Sciences

College of Veterinary Medicine

Kansas State University

1800 Denison Ave.

Manhattan, KS 66506

(785)532-5700

BWhite@vet.ksu.edu

$\mathrm{RL}$ Larson and BJ White have received grants, or research contracts, from the National Cattlemen's Beef Association, the United States Department of Agriculture, Zoetis Animal Health, Merck \& Company, CEVA Biomune, Boehringer Ingelheim Vetmedica, and Merial Animal Health.

Key Words: reproductive profile, fetal aging, breeding soundness examination, pregnancy loss

\section{Key Points}

- Diagnosis of pregnancy status for beef herds is commonly done at a time point in midgestation that is early enough to allow accurate estimation of fetal age, but late enough to facilitate evaluation of the first three 21-day periods of the breeding season.

- Breaking the fetal age estimation data collected at the time of pregnancy diagnosis into separate reproductive profiles based on cow age category, breed, breeding pasture, or other management group is often necessary to accurately identify deficiencies in herd reproductive efficiency and to direct the investigation to the correct sub-set of the cow herd.

- By starting with the flow of beef cows through the reproductive system and gathering fetal age estimation at the time of pregnancy diagnosis, veterinarians can use reproductive profiles and other readily available information to systematically go through a decision tree to diagnose reproductive inefficiency and to advise producers where areas of improved reproductive efficiency are available for their herds. 


\begin{abstract}
Good reproductive efficiency and low pregnancy wastage are critical for economic sustainability of beef cow-calf herds. Two standard measurements of reproductive success for beef cowherds are the percentage of cows exposed to bulls at the start of the breeding season that are identified as pregnant at a mid-gestation evaluation, and the percentage of pregnant cows that give birth to a live calf. In addition to these standard performance assessments, converting fetal age data to a reproductive profile (or pregnancy distribution) that displays pregnancy percentages by 21-day periods can provide enhanced information to assist in the diagnostic work-up for sub-optimal reproductive efficiency and to guide the design of intervention strategies. The value of fetal age data can be amplified by further segregating reproductive profiles by animal age and/or other management groups when evaluating a herd with reproductive or production shortfalls.

\section{Introduction}

Good reproductive efficiency and low pregnancy wastage are critical for economic sustainability of beef cow-calf herds. Two standard measurements of reproductive success for beef cowherds are the percentage of cows exposed to bulls at the start of the breeding season that are identified as pregnant at a mid-gestation evaluation, and the percentage of pregnant cows that give birth to a live calf. In addition to these standard performance assessments, converting fetal age data to a reproductive profile (or pregnancy distribution) that displays pregnancy percentages by 21-day periods can provide enhanced information to assist in the diagnostic work-up for sub-optimal reproductive efficiency and to guide the design of intervention strategies. The value of fetal age data can be amplified by further segregating reproductive profiles by animal age and/or other management groups when evaluating a herd with reproductive or production shortfalls. ${ }^{1-4}$
\end{abstract}

\title{
"Flow" of cows through potential reproductive states during a production-cycle
}

From a reproductive standpoint, mature female cattle should pass through a series of "states" each year. (Figure 1)

- Starting in late pregnancy, a cow moves from the "state of pregnancy" prior to calving to the "state of being non-pregnant but not having fertile ovulations" once parturition has completed. (Figure 1)

- Beef cows have a period of time after calving, called postpartum anestrus, when they do not display the behavioral aspects of estrus necessary to initiate mating and they do not ovulate fertile eggs. Postpartum anestrus in multiparous (mature) cows averages about 50-80 days if the cows are in good body condition ${ }^{5,6}$ and requires an estimate of 70 to 100 days to reach a herd-goal of $90 \%$ of cows resuming fertile cycles. 
- This period of time is longer if cows are thin and following the first (primiparous) pregnancy (average of 80 to 100 days) ${ }^{7,8}$ compared to later (multiparous) pregnancies (50-80 days).

- A cow will resume ovulating fertile eggs every 21 days once the postpartum anestrus period is passed and she enters the "state of being non-pregnant and having fertile 21-day estrous cycles". (Figure 1)

- If a fertile, cycling cow is in the presence of a fertile bull, the subsequent mating has about a 60 to $70 \%$ probability of a pregnancy that can be detected 50 days later and consequently a calf being born at the end of gestation. ${ }^{9}$

- Following approximately $30 \%$ of matings between a fertile female and a fertile bull either fertilization fails to take place or fertilization occurs but the early embryo is not maintained. When fertilization fails or an embryo is lost before day 14 of gestation, the cow will express estrus and ovulate a fertile oocyte about 21 days after her last estrus and have another 60 to $70 \%$ probability of conceiving and maintaining a pregnancy.

- Upon mating with a fertile bull and subsequent conception and maintenance of a pregnancy, cows move to the state of being "pregnant" until parturition. (Figure 1)

- There are several alternative pathways in this system including: failure to conceive, early gestation pregnancy loss, late gestation pregnancy loss, and delivery of a stillborn calf.

\section{PLACE FIGURE 1 HERE}

\section{Creating herd reproductive profiles from information obtained from diagnosis of pregnancy status of beef herds}

- Diagnosis of pregnancy status for beef herds is commonly done at a time point in mid-gestation that is early enough to allow accurate estimation of fetal age, but late enough to facilitate evaluation of the first three 21 -day periods of the breeding season. ${ }^{10}$

- The stage of gestation where estimation of fetal age begins to become less accurate varies between veterinarians, but accuracy of gestational staging to 21 day cycles tends to decline at gestational lengths above 100 days.

- A pregnancy evaluation done 105 days after the start of the breeding season allows veterinarians comfortable with determining pregnancy status starting at 40 days of gestation to describe cows with estimated gestational lengths of 85 to 105 days, 64 to 84 days, and 43 to 63 days as conceiving in the first, second, and third 21 days respectively (Figure 2 ).

\section{PLACE FIGURE 2 HERE}

- The ability to estimate fetal age accurately enough to place females within fairly tight "stages" or 21 day periods of the breeding season is a great advantage for veterinarians providing advice to cow-calf clients when evaluating the nutritional and 
reproductive status of the herd's recent past and in planning to optimize the upcoming nutritional and marketing options for the herd.

- If fetal age estimates are not available, recording the date of calving for each individual (or at least the number of calves born each 21-day period) also allows producers to generate calving distribution profiles; however, by analyzing pregnancy distribution soon after the end of the breeding season, information is generated 6 to 7 months earlier.

- The most common method of analyzing pregnancy data is to break the breeding season into 21 day periods. Then, for further diagnostic power, the breeding season can be broken down another level, into two or more categories by 21 day periods.

Categories analyzed can include: age, breed, pasture, or other management groups. Gestational age data can be collected and displayed while on-farm by using handwritten grids (Figure 3 ) or with computer-generated spread sheets (Figure 4).

PLACE FIGURE 3 HERE

PLACE FIGURE 4 HERE

\section{Link to Pregnancy Histograms Spreadsheet}

- For a 60 to 65 day breeding season, the ideal profile should resemble Figure 5. Producers should strive for nutritional and management systems that allow 60 to $65 \%$ of the exposed females to become pregnant in the first 21 days of the breeding season. ${ }^{11}$ The majority of the remaining females should become pregnant in the second 21 day period. And, $5 \%$ or less of the herd should be non-pregnant at the end of the 60-65 day breeding period.

PLACE FIGURE 5 HERE

- Once fetal age data is collected and organized for analysis, conclusions or further questions may present themselves. If the data meets the criteria depicted in Figure 5 , the breeding season can be considered a success and further diagnostics are probably not warranted. If however, the profile is less than ideal, further evaluation should be done to determine the cause.

\section{Investigation of less-than-ideal herd reproductive profiles}

- If a client is concerned that too few calves are born alive from the cows that entered the breeding season, a veterinarian looking at the flow of cows through the reproductive cycle (Figure 1) will recognize that the potential pathways that result in 
calves not being born alive include: failure to conceive, early gestation pregnancy loss, late gestation pregnancy loss, and birth of stillborn calves.

- Fortunately, the most likely rule-outs for the various alternate pathways that result in cows that enter the breeding season failing to give birth to live calves are largely mutually exclusive.

- In contrast to only evaluating low overall pregnancy success, the reproductive profile can provide information to narrow the list of potential causative factors for the reproductive loss. For example, when low pregnancy success is identified, there are many potential causes, but they fall into several broader categories. (Figure 6). The reproductive profile can help identify which broad category is most likely.

\section{PLACE FIGURE 6 HERE}

\section{Failure to conceive}

\section{Failure to conceive - cow problems}

\section{PLACE FIGURE 7 HERE}

- Failure to conceive due to cow or heifer problems related to: displaying the behavioral characteristics of estrus necessary to induce mating, ovulating a fertile oocyte, or maintaining an early embryo is due to factors that occur prior to or during the breeding season (Figure 7).

- Since gestation lasts about 283 days, cows must become pregnant again within 82 days after calving in order to maintain a 365 day calving interval. Because of the biologic constraints listed previously (70 to 100 day or more period until $90 \%$ of cows have retained postpartum fertility and 60 to $70 \%$ expected successful pregnancies from matings of fertile bulls and cows), the number of cows cycling at the start of the breeding season is greatly influenced by the immediately preceding calving distribution (and calving distributions of prior years). In other words:

- The term "momentum" is used to describe the reality of beef herd reproduction that last year's breeding and calving season pattern is an important predictor of this year's breeding season pattern.

- Although calving distributions can become much less than ideal in a single year, it is very difficult to improve calving distributions in a single year (or even over several years).

- Herds that have $50 \%$ of cows cycling by the end of the first 21-days of the breeding season are expected to have 30 to $35 \%$ of the herd become pregnant in the first 21 days (60 to $70 \%$ pregnancy success from the mating of fertile cows to fertile bulls).

- Herds may only have $50 \%$ cycling at the start of the breeding season because only one-half of the herd calved early enough to complete the period of postpartum anestrus by the end of the first 21 days of breeding.

- The 30 to $40 \%$ of cycling, fertile cows that failed to maintain a pregnancy from the first mating will have a second 60 to $70 \%$ probability of establishing a successful pregnancy 21 days later. The previously cycling cows will be 
joined by the portion of the herd that resumes cycling during the second 21 days - this results in approximately another $30 \%$ of the herd establishing a pregnancy during the second 21 days of breeding.

- Herds that have approximately $50 \%$ of cows cycling by the end of the first 21 days of the breeding season will have a flat pregnancy distribution that will require 4 or more 21 -day periods to reach $95 \%$ of the herd establishing a successful pregnancy. (Figure 8)

\section{PLACE FIGURE 8 HERE}

- A herd with a previously front-end loaded distribution similar to Figure 5 that calves in thin body condition and/or that loses body condition after calving will have prolonged periods of post-partum anestrous and can have a pregnancy distribution similar to Figure 8 within a year or two once the percentage of cows that have resumed fertile cycles by the end of the first 21 days of breeding drops to $50 \%$ or fewer.

- If the breeding season is confined to 60 to 65 days, approximately $15 \%$ of the herd would be expected to be non-pregnant - even though the cows are fertile and mated to fertile bulls. (Figure 8 )

- This profile is expected to be repeated the following breeding season, because nearly all the cows that calve in the first 21 day period and about one-half the cows that calve in the second 21-day period are expected to resume fertile cycles by the end of the first 21 days of the next breeding season $(35 \%+15 \%=50 \%)$ - the same percentage of cycling cows that created the current distribution.

- If a reproductive profile similar to Figure 8 is due to a high percentage of the herd not resuming fertile cycles until the second or later 21-day period of breeding, palpation of the reproductive tracts of the non-pregnant cows should not reveal evidence of pregnancy loss (i.e. involuting uterus).

- The magnitude of non-pregnant cows at the end of the breeding season will depend on the length of the breeding season and the percentage of the herd that are cycling by the end of the first 21 days of breeding.

- Even if the breeding season is limited to 63 days and postpartum anestrus is prolonged, at least $80 \%$ of the cows are expected to be pregnant if the problem is confined to issues of cows resuming fertile estrous cycling during the breeding season.

- A magnitude of non-pregnant cows that exceeds $20 \%$ of the herd is not likely due to cow-problems alone and either bull problems or a combination of cow-problems and bull-problems should be investigated.

Failure to conceive - bull problems 
- Because bulls are responsible to establishing viable pregnancies in multiple cows, bull failure can result in a high percentage of the herd being non-pregnant, particularly if the breeding season is limited to 60 to 65 days.

- Any time that reproductive efficiency during a breeding season suddenly decreases, bull problems should be considered likely.

- Single-bull breeding pastures are particularly prone to a high percentage of nonpregnant cows if bulls do not successfully breed cycling, fertile cows.

- The magnitude of pregnancy loss due to an infertile bull in a single sire pasture can be extremely high and combined with sudden onset may be pathognomonic for a bull problem.

PLACE FIGURE 9 HERE

\section{- Bull problems at a point after the start of the breeding season}

Decrease in percent of open cows becoming pregnant from one 21-day period to the next does not have to be as obvious or drastic as that depicted in Figure 9 for bull problems to be the most likely cause of reproductive inefficiency.

- Populations of fertile, cycling cows are not likely to have a sudden decrease in the percentage having fertile cycles because reduction in cow fertility due to body condition change usually requires several weeks and severe disruptions in nutrient intake.

- Because the breeding season depicted in Figure 9 starts with good reproductive success, the bull(s) associated with this problem would have passed a Breeding Soundness Examination of bulls (BSEB) prior to the start of breeding. In addition, a BSEB done after the breeding season may or may not provide indications of subfertility, depending on the type of insult and the length of time between the insult and the BSEB.

- Bull problems at the start of the breeding season

A herd with too few bulls for the number of cycling cows, a herd with a single bull recovering from an injury or disease, or a herd with a group of bulls that are subfertile at the start of breeding (e.g. peri-pubertal bulls) but that regain or obtain normal fertility as the breeding season progresses may or may not include a history of passing a BSEB prior to the start of the breeding season, but if a BSEB is utilized after the breeding season as part of the reproductive inefficiency investigation, the bulls are likely to pass. (Figure 10)

- A BSEB should be performed prior to the start of the breeding season on all bulls in the breeding program. Although a satisfactory BSEB does not eliminate bull sub-fertility as a rule-out for poor breeding performance, a questionable breeder as determined by BSEB may impact the female:fertile bull ratio if not replaced. Failure to obtain a BSEB on all bulls leaves bull 
fertility at the start of the breeding season as an unknown variable among possible rule-outs when investigating poor herd-level reproductive performance.

- A BSEB (including a through physical examination) at the time the breeding season problem is discovered may supply information about penile, testicular, foot and leg or other musculoskeletal health problems during the breeding season. However, lack of identifiable pathology during an examination following the breeding season does not rule-out a physical (locomotion, mounting, intromission) or semen quality problem and an associated female:fertile bull ratio inadequacy that impaired successful mating earlier in the breeding season.

\section{PLACE FIGURE 10 HERE}

- Multiple-bull breeding pastures are resilient to breeding failure due to the inability of a single bull to successfully mate cows. But because of potential problems arising from injuries due to bull-on-bull fighting, social dominance by subfertile bulls, and isolation of groups of cows without one or more bulls present in an extensive breeding pasture, multiple-bull pastures can also have poor reproductive efficiency due to bull problems and have reproductive profiles similar to Figures 9 or 10.

- The reproductive profile depicted in Figure 8 can be due to cows not cycling at the start of the breeding season or due to bull problems that result in sub-optimum breeding success such that only 40 to $50 \%$ of matings with fertile, cycling cows result in a viable pregnancy.

- If a reproductive profile similar to Figures 8,9 , or 10 is due to bull sub-fertility or inability to successfully mate, palpation of the reproductive tracts of the nonpregnant cows should not reveal evidence of pregnancy loss (i.e. involuting uterus).

- The magnitude of non-pregnant cows at the end of the breeding season will depend on the number of cycling cows per fertile bull and the length of the breeding season. But any reproductive profile that indicates that $15 \%$ or more of cows are not pregnant after the first 63 days of the breeding season is sufficiently suggestive of bull problems to justify further investigation of bull fertility.

\section{Early gestation pregnancy loss}

\section{PLACE FIGURE 11 HERE}

- Infection with the protozoa Trichomonas foetus (Trich) is an important cause of early gestational pregnancy loss in North America because it is present in many cattledense areas of the continent and because it can cause a high percentage of exposed cows to lose their pregnancies (Figure 11). 
- The pregnancy profile of a herd infected with Trich will vary depending on what the profile would have been without infection and the timing of Trich introduction into the herd.

- If Trich entered the herd prior to the start of the breeding season so that a high percentage bulls are already infected, the cows will become pregnant at a time similar to last year's breeding season, but infected cows are likely to lose their pregnancies approximately 15 to 80 days into gestation, at which time the embryo or fetus dies and is resorbed or aborted. A period of female infertility is expected to last for another two to six months as a result of infection. The magnitude of loss is expected to approach $30 \%$ to $50 \%$ of exposed cows (Figure 12).

\section{PLACE FIGURE 12 HERE}

- If Trich entered the herd during the breeding season, or only a few bulls were infected at the start of the breeding season but the number of infected bulls increased as the breeding season progressed, then the reproductive profile is greatly influenced by what the profile would have been without Trich exposure, and the speed at which additional bulls become infected. (Figure 13)

- If few bulls are Trich-infected at the start of breeding, only a few cows that become pregnant during the first 21 days are mated by Trich-infected bulls so few pregnancies are lost from this portion of the breeding season.

- By the second 21-days of breeding, more bulls have become infected with Trich and cows mated by positive bulls may lose their pregnancies.

- And, by the third 21-days, many cows are mated by Trich-infected bulls and about $40 \%$ (30\% to $50 \%)$ of these cows will lose their pregnancy.

- Most cows that become pregnant from mating by Trich-infected bulls in the first two 21-day cycle will be non-pregnant by the time of pregnancy diagnosis, but some later-conceiving cows may not abort due to Trich until after the time of pregnancy diagnosis.

\section{PLACE FIGURE 13 HERE}

- If any disease-causing organism or toxin causes early gestational loss, palpation of the reproductive tracts of the non-pregnant cows relatively soon after pregnancy loss should reveal evidence of that loss in some of the affected cows (i.e. involuting uterus).

- The magnitude of non-pregnant cows at the end of the breeding season will depend on when in the breeding season the herd becomes infected with Trich and the percentage of the bulls in the breeding pasture that become infected. If a high percentage of bulls are infected for most of the breeding season, the magnitude of pregnancy loss is expected to be very high (e.g. 20 to $50 \%$ fewer pregnancies than expected) and evidence of pregnancy loss is likely to be found upon palpation of the non-pregnant cows' uteri. 
- Other causes of early gestational pregnancy loss (e.g. Campylobacter fetus ss venerialis, Bluetongue virus, Leptospira borgpetersenii serovar hardjo type hardjobovis, bovine viral diarrhea virus) will have a similar effect on the reproductive profile but the magnitude of pregnancy loss is not expected to be as high as with Trich. (Larson 1996; BonDurant 2007)

\section{Late gestation pregnancy loss}

\section{PLACE FIGURE 14 HERE}

- Infectious, toxic, and nutritional causes of pregnancy loss that are expected to be most commonly expressed in mid- to late-gestation include: bovine herpes virus 1 (Infectious Bovine Rhinotracheitis - IBR), bovine viral diarrhea virus (BVDv), Neospora caninum, Leptospira sp., epizootic bovine abortion, pine-needle toxicosis, and others (Figure 14). ${ }^{12,13}$

- Pregnancy losses in mid- to late-gestation are likely to occur after the time of pregnancy diagnosis; therefore, the profile as determined at the time of pregnancy diagnosis will look similar to the proceeding calving pattern. If some losses occurred prior to the time that pregnancy status is determined, evidence of that loss is likely to be found upon palpation of the non-pregnant cows' uteri.

- The magnitude of pregnancy loss due to mid- to late-gestation infectious, toxic, and nutritional will depend on the agent, toxin, or nutrient involved, the percentage of the herd that is most susceptible at the time of the insult, and the immune status of the herd. Except in unusual situations of concurrent high susceptibility and exposure, the percent of cows that lose their pregnancy is expected to be relatively low and much lower than losses associated with bull failure or Trich exposure.

\section{Stillbirth loss}

\section{PLACE FIGURE 15 HERE}

- Pregnancy losses in at the end of gestation will, by definition, occur after the time of pregnancy diagnosis and therefore, the reproductive profile is not affected. (Figure 15)

- Available records gathered at the time of calving as well as questions directed to the cow-calf producer that specifically defines the number of stillborn calves or calves that die shortly after birth will determine whether excessive calf losses should be investigated. 


\section{Second-level analysis of gestational age data}

- To capture more information from reproductive profiles, the distribution of breeding dates can be analyzed not only by 21 -day intervals, but also by category within those 21 -day intervals. The herd depicted by Figure 16 has an overall pregnancy proportion of $91 \%$, which is less than the goal of $95 \%$ following a 63 -day breeding season, but is not alarming. In addition, the percentage of the herd that became pregnant during the first 21 days of the breeding season is near our goal of $65 \%$. From these observations, one could conclude that the herd has normal fertility and that there are no reproductive management problems.

\section{PLACE FIGURE 16 HERE}

- A closer examination of the information gathered while determining pregnancy status of the herd reveals a much different conclusion.

- The herd depicted in Figure 16 consists of heifers (nulliparous heifers), first-calf heifers (primiparous cows), and mature (multiparous) cows. Estrous synchronization and artificial insemination was utilized in the heifers. The rest of the cowherd was exposed to five bulls that had each passed a BSEB prior to the start of the breeding season.

- The data depicted in Figure 16 is further analyzed by breaking it into four separate evaluations for each 21-day period: the overall proportion of pregnancy, the proportion of pregnancy for the heifers, the proportion of pregnancy for first-calf heifers (primiparous cows), and the proportion of pregnancy for the mature (multiparous) cows. (Figure 17)

\section{PLACE FIGURE 17 HERE}

- Although the overall pregnancy distribution for this herd is not alarming, a very poor reproductive profile for the first-calf heifers (primiparous cows) indicates that management for this herd is not satisfactory. Not only are more than one-half of the open animals from the first-calf heifer group, the percentage pregnant during the first 21 days of the breeding season for this group is also unacceptable.

- Breaking the fetal age estimation data collected at the time of pregnancy diagnosis (or calving date data collected at calving) into separate reproductive profiles based on cow age category, breed, breeding pasture, or other management group is often necessary to accurately identify deficiencies in herd reproductive efficiency and to direct the investigation to the correct sub-set of the cow herd.

\section{Summary - Pregnancy distributions are one of several important pieces of diagnostic data used by veterinarians evaluating beef herd reproduction}

- Information obtained at the time of diagnosis of pregnancy status to evaluate beef herd reproduction: 


\section{- Reproductive profile (Pregnancy Distribution)}

Pregnancy distributions created from data collected at the time of pregnancy diagnosis often do not provide definitive answers in herd fertility investigations because one or more factors may cause or may combine to cause a specific distribution and a single cause may manifest itself as more than one reproductive profile. However, pregnancy distributions are a powerful diagnostic tool in the investigation of beef cow herd reproductive performance.

- Characteristics of non-pregnant uteri per palpation Palpable evidence of cows with an involuting uterus or a retained placenta provide proof of recent pregnancy loss which could be the remnants of a herd problem of early gestation loss or the beginnings of late gestation pregnancy loss.

- Additional Information to evaluate beef herd reproduction

- Comprehensive BSEB prior to the start of the breeding season, including determination of bull:cow ratio in breeding pasture(s) (or confirmation of absence of bull BSEB).

- Calving distribution of the just-completed calving season

- Pregnancy distribution (or calving distribution) from previous years' (one or more) reproductive performance.

- Breeding soundness examination of replacement (nulliparous) heifers prior to breeding season (percent cycling, reproductive tract score, body weight, pelvic area, etc.).

- Estimation of the percentage of first-calf heifers (primiparous cows) that have resumed fertile cycles by the start of the breeding season for their second pregnancy by palpation or ultrasound examination for presence of corpus luteum, observation for expression of estrus (with or without heat detection aids), or measurement of progesterone levels in blood.

- Estimation of the risk of herd exposure to Trich, BVDv, IBR, pine needs, or other abortion-causing agents and biosecurity and management factors that contribute to increased or decreased risk.

- If mid- to late-gestation pregnancy loss is identified as the problem, a rule-out list of infectious agents or toxins that cause late gestation losses can be investigated with specific diagnostic tests for the most likely rule-outs.

- If early-gestation pregnancy loss is identified as the problem, then physical examination findings and diagnostic tests specific for infectious, toxic, and physiologic insults that are associated with early gestation loss can be initiated. 
- If failure-to-conceive is identified as the problem, breeding soundness examination findings of bulls, breeding soundness examination findings of replacement heifers, and herd records can be used to indicate whether a male infertility or female infertility problem is the most likely cause.

- Once the distinction of which sex is mostly likely associated with the conception failure, specific diagnostic tests or examination of records can be used to investigate the principle male or female problem.

- By starting with the flow of beef cows through the reproductive system and gathering fetal age estimation at the time of pregnancy diagnosis, veterinarians can use reproductive profiles and other readily available information to systematically go through a decision tree to diagnose reproductive inefficiency and to advise producers where areas of improved reproductive efficiency are available for their herds.

\section{References}

1. Spire MF. Breeding season evaluation of beef herds. In: Howard JF, ed. Current Veterinary Therapy, ed. 2. Philadelphia, WB Saunders, 1986;808-811.

2. Randle RF. Production medicine considerations for enhanced reproductive performance in beef herds. Vet Clinics of N America 1993;9:404-415.

3. Larson RL. Evaluating information obtained from pregnancy examination in beef herds. Veterinary Medicine 1999;94:566-576.

4. White BJ. Beef Herd Record Analysis. In: Bovine Reproduction, Ed. R. Hopper. Wiley-Blackwell, Oxford, UK 2015:364-369.

5. Cushman RA, Allan MF, Thallman RM, et al. Characterization of biological types of cattle (Cycle VII): Influence of postpartum interval and estrous cycle length on fertility. J Anim Sci 2007;85:2156-2162.

6. Lents CA, White FJ, Ciccioli NH, et al. Effects of body condition score at parturition and postpartum protein supplementation on estrous behavior and size of the dominant follicle in beef cows. J Anim Sci 2008;86:2549-2556.

7. Ciccioli NH, Wettemann RP, Spicer LJ, et al. Influence of body condition at calving and postpartum nutrition on endocrine function and reproductive performance of primiparous beef cows. J Anim Sci 2003;81:3107-3120, 2003.

8. Berardinelli JG, Joshi PS. Introduction of bulls at different days postpartum on resumption of ovarian cycling activity in primiparous beef cows. J Anim Sci 2006;83:2106-2110.

9. BonDurant RH. Selected diseases and conditions associated with bovine conceptus loss in the first trimester. Theriogenology 2007;68,461-473.

10. Bretzlaff K. A pictorial guide to bovine pregnancy diagnosis. Veterinary Medicine 1987;82:295-304. 
11. Kasari T, Gleason D. Herd management practices that influence total beef calf production - Part I. Comp Cont Ed Pract Vet 1996;18:823-832.

12. Larson RL. Diagnosing the cause of bovine abortion and other perinatal deaths. Veterinary Medicine 1996;91:478-486.

13. Anderson ML. Infectious causes of bovine abortion during mid- to late-gestation. Theriogenology 2007;68:474-486.

\section{Figure Legends}

Figure 1. Beef cattle females flow through specific reproductive "states": Not pregnant and not ovulating fertile oocytes, Not pregnant and ovulating fertile oocytes every 21 days, Pregnant, Pregnant at the time of pregnancy detection, and Pregnant at the completion of gestation. There are several alternative pathways in this system including: failure to conceive, early gestation pregnancy loss, late gestation pregnancy loss, and delivery of a stillborn calf.

Figure 2. Approximate timing of diagnosis of pregnancy status in beef herds in relationship to the beginning of the breeding season.

Figure 3. Example of form for hand-written data collection and display.

Figure 4. Example of spread-sheet generated data display.

Figure 5. Pregnancy distribution goal for a 63-day breeding season.

Figure 6. Example algorithm for investigating poor pregnancy success highlighting the broad categories of largely mutually-exclusive rule-out lists.

Figure 7. In situations when "Failure to Conceive" leads to a poor reproductive profile, the problem occurred prior to the time of pregnancy diagnosis and the causes must have occurred during the breeding season (bull problems) or during the breeding season because of factors starting at or before calving (cow problems). In addition, few if any cows have palpable evidence of an involuting uterus or a retained placenta indicating pregnancy loss. 
Figure 8 . Typical reproductive profile for herd with $50 \%$ of cows cycling by the end of the first 21 days of the breeding season.

Figure 9. Pregnancy distribution in a single-bull herd where cows are cycling at the start of the breeding season, the bull is successfully mating cows, but an acute onset of bull infertility occurs at the end of the first 21 days of the breeding season (such as injury, disease, etc.) followed by a period of partial recovery.

Figure 10. Pregnancy distribution of a herd with fertile, cycling cows, but subfertile bulls at the start of the breeding season, but bulls obtain or recover normal fertility, or the ratio between fertile bulls and cycling cows improves as cows become pregnant as the breeding season progresses. The percent of non-pregnant cows becoming pregnant each 21 -day period $\left(1^{\text {st }}\right.$ through $\left.4^{\text {th }}\right)$ is: $25 \%, 40 \%$, $67 \%$, and $67 \%$.

Figure 11. In situations when "Early Gestation Pregnancy Loss" leads to negative effects on the reproductive profile, the problem occurred after the breeding season started and probably before the time of pregnancy diagnosis. The overall pregnancy percentage and the distribution of pregnancies is expected to be impacted by early pregnancy loss. In addition, some of the non-pregnant cows are likely to exhibit palpable evidence of an involuting uterus as evidence for recent pregnancy loss.

Figure 12. Pregnancy distribution of a herd where a high percentage of bulls are infected with Trich at the start of the breeding season. About $40 \%$ (30\% to $50 \%$ ) of the cows that become pregnant during each 21 -day cycle will lose their pregnancy. Most cows that become pregnant in the first two 21-day cycle will be non-pregnant by the time of pregnancy diagnosis, but some later-conceiving cows may resorb or abort the fetus due to Trich after the time of pregnancy diagnosis.

Figure 13. Pregnancy distribution of a herd where few bulls are infected with Trich at the start of the breeding season but over the breeding season, many become infected.

Figure 14. In situations when "Late Gestation Pregnancy Loss" leads to pregnancy wastage, the problem likely reveals itself after pregnancy diagnosis; therefore, the reproductive profile based on data collected at pregnancy diagnosis may not be affected. Evidence of abortion or failure to calve in cows that were diagnosed as pregnant in mid-gestation indicates a late gestation pregnancy loss problem, and comparison of calving profiles to pregnancy profiles can be very helpful in the investigation. 
Figure15. In situations when "Stillbirth Loss" leads to pregnancy wastage, the reproductive profile based on data collected at pregnancy diagnosis would not be affected.

Figure 16. A nearly ideal pregnancy distribution in a herd with a "hidden" breeding season problem.

Figure 17. Pregnancy distribution for each 21-day period in a 63-day breeding season, analyzed by age group. 


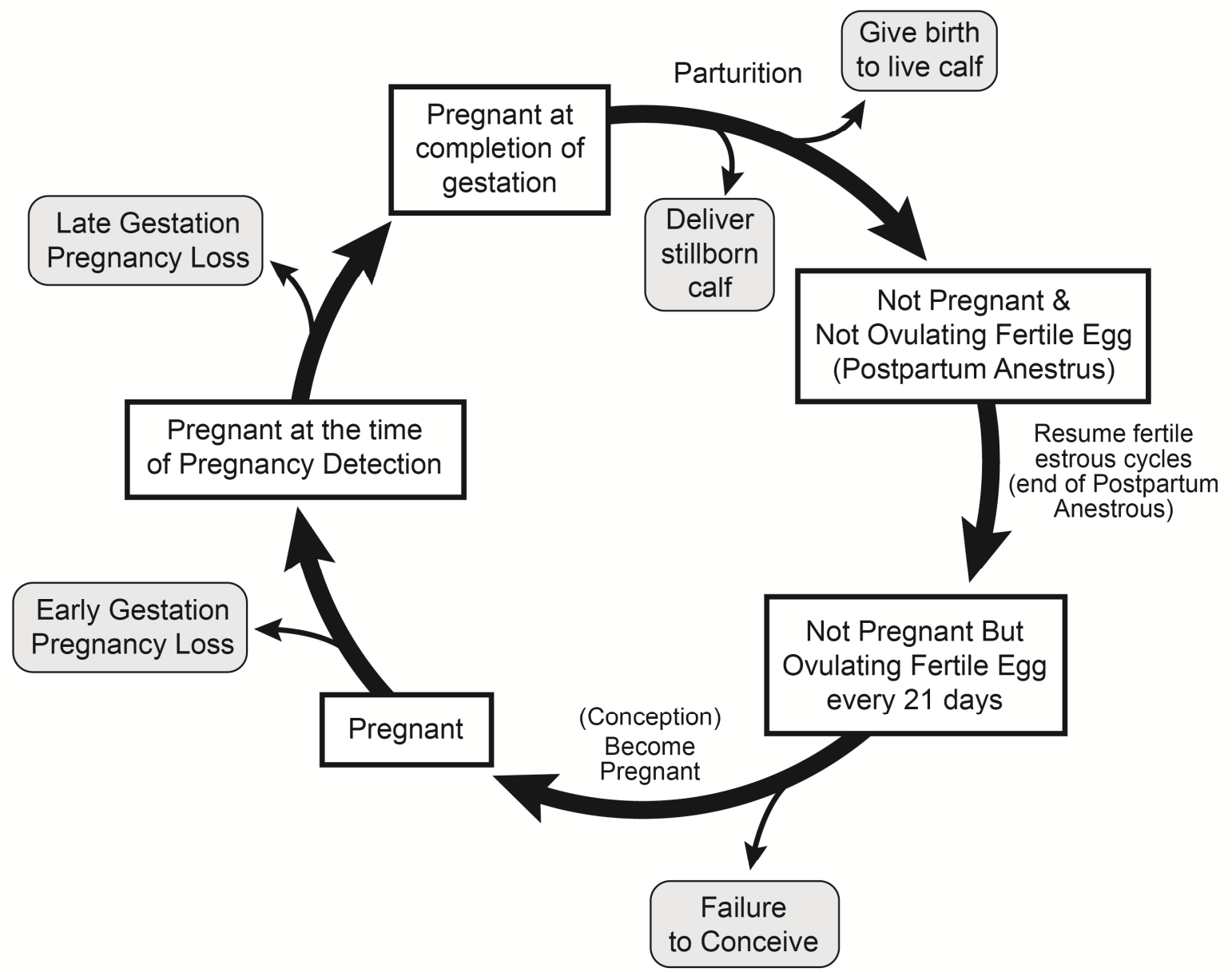




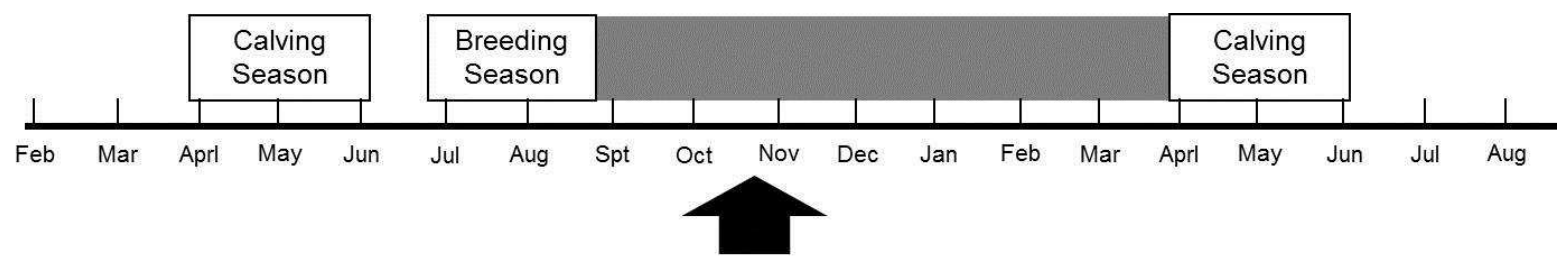

\section{Preg Check}




\section{Beef Cattle Veterinary Services \\ Anywhere, USA \\ Pregnancy Distribution Evaluation}

Farm Diamond Bar J Dr. H.0. JoHnSON Date 10/3/16 Breeding Season Starts $6 / 5 / 16$ Ends $8 / 20 / 16$ \# Head 89

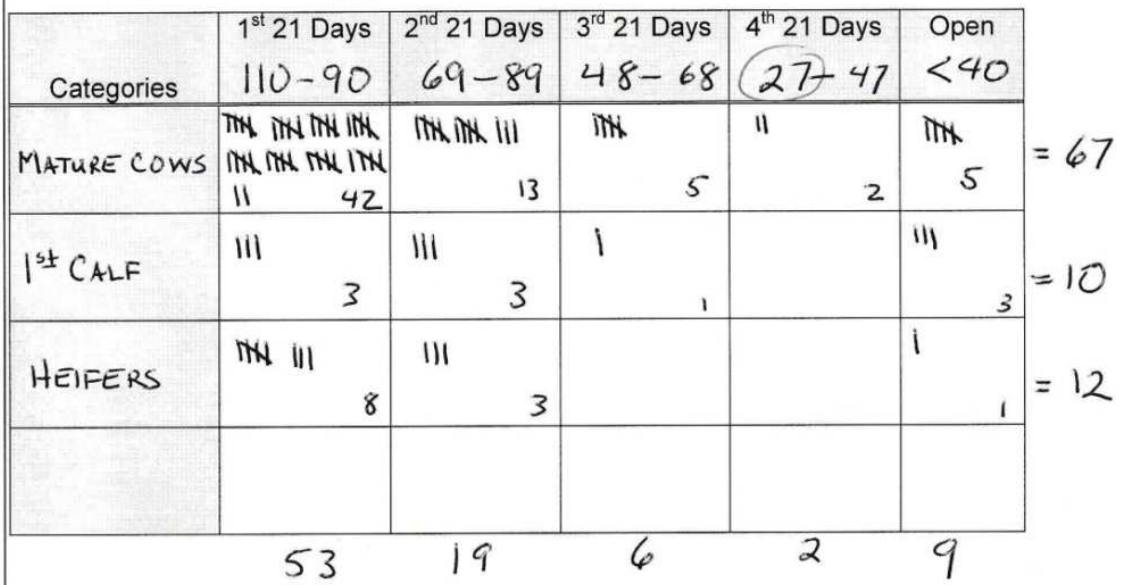

Report

\begin{tabular}{|l|c|c|c|c|c|c|}
\hline \multirow{2}{*}{ Categories } & \multicolumn{2}{c|}{$1^{\text {st }}$ 21 Days } & \multicolumn{2}{c|}{1 1st 63 Days } & \multicolumn{2}{c|}{ Total } \\
\hline Overall & $53 / 89$ & 59.6 & $78 / 89$ & 87.6 & $80 / 89$ & 89.9 \\
\hline 1) MATURE COWS & $42 / 67$ & 62.7 & $60 / 67$ & 89.5 & $62 / 67$ & 92.5 \\
\hline 2) 1 (L CALF & $3 / 10$ & 30 & $7 / 10$ & 70 & $7 / 10$ & 70 \\
\hline 3) HEIFERS & $8 / 12$ & 66.7 & $11 / 12$ & 91.7 & $11 / 12$ & 91.7 \\
\hline 4) & & & & & & \\
\hline & & & & & & \\
\hline
\end{tabular}

Comments:

3 BULS AT TURN-OUT, I REMOVED $7 / 8 / 1 C$ (INJURY) 


\section{Kansas State University, College of Veterinary Medicine Bob L. Larson, DVM, PhD \\ Pregnancy Histograms}

Ranch Name Diamond Bar J

Date of pregnancy detection

Beginning of breeding season (date)

End of breeding season (date)

30-Sep-16

10-Jun-16

15-Aug-16
No. of days in breeding

Max Days Preg

Min Days Preg

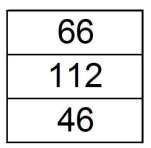

Breed 1 =

Breed 2 =

Breed $3=$

Breed 4=

\begin{tabular}{|c|c|}
\hline Hereford Cross & Age choices are: heifer, first calf heifer, and cow \\
\hline Angus Cross & Body Condition Score (3-7) \\
\hline AngusXChar & Optional category can have up to 3 options (1-3) \\
\hline
\end{tabular}

\section{Total pregnancy $\%$}

$\%$ preg

82.09

$\%$ open

17.91

Number preg Number open

55

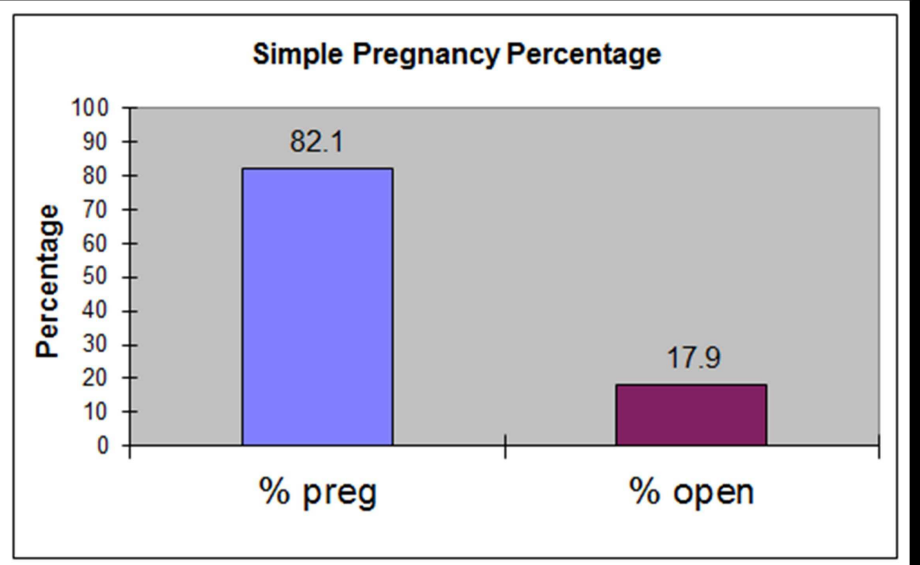

Percentage by age in each 21-d interval

First

Second

Third

Fourth

Fifth

Open

Preg

Total \#

\begin{tabular}{|c|c|c|}
\multicolumn{1}{c}{ Heifer } & Heifer & \multicolumn{1}{c}{ Cow } \\
\hline 62.50 & 50.00 & 45.16 \\
\hline 18.75 & 20.00 & 29.03 \\
\hline 6.25 & 5.00 & 12.90 \\
\hline 0.00 & 0.00 & 0.00 \\
\hline 0.00 & 0.00 & 0.00 \\
\hline 12.50 & 25.00 & 12.90 \\
\hline 87.50 & 75.00 & 87.10 \\
\hline 16 & 20 & 31 \\
\hline
\end{tabular}

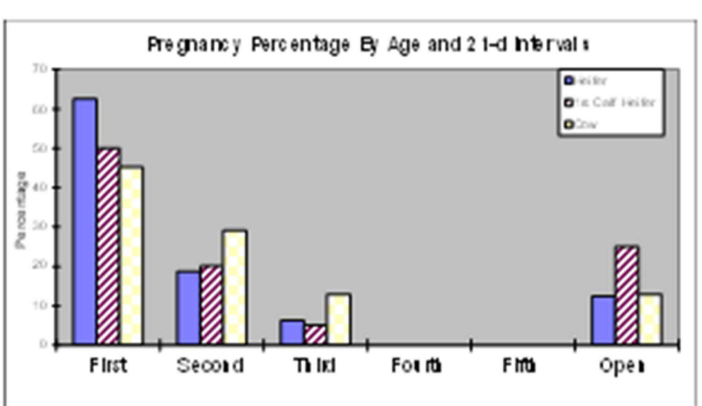




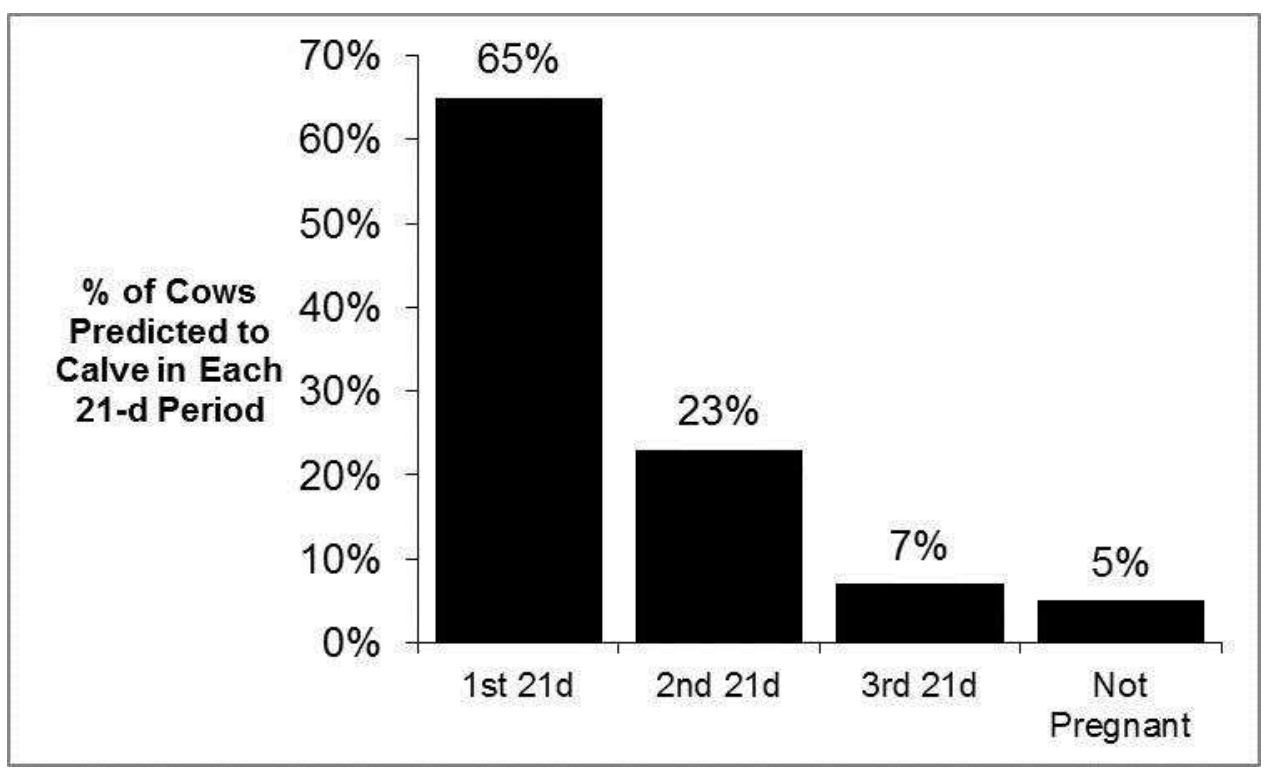




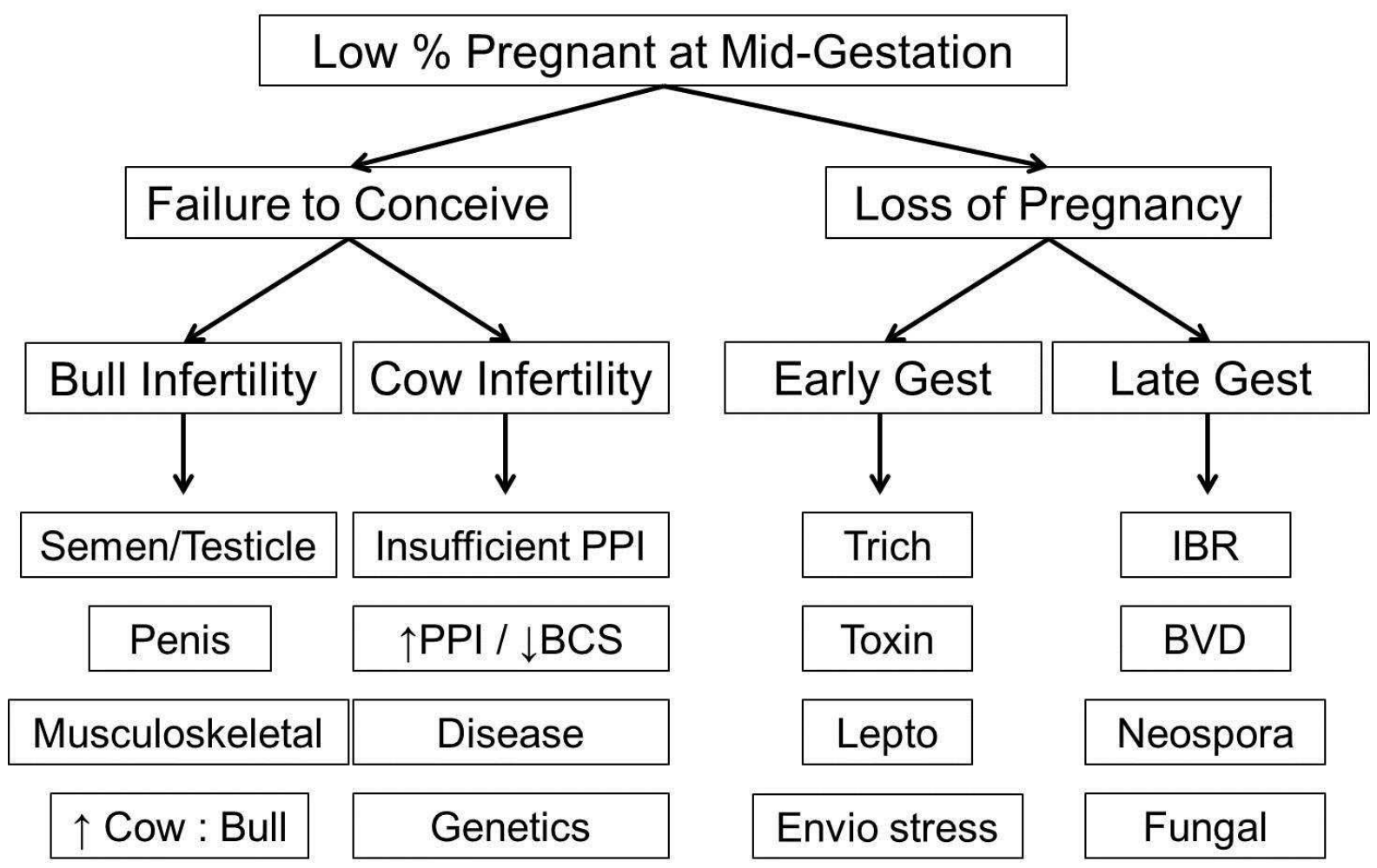


Failure to Conceive

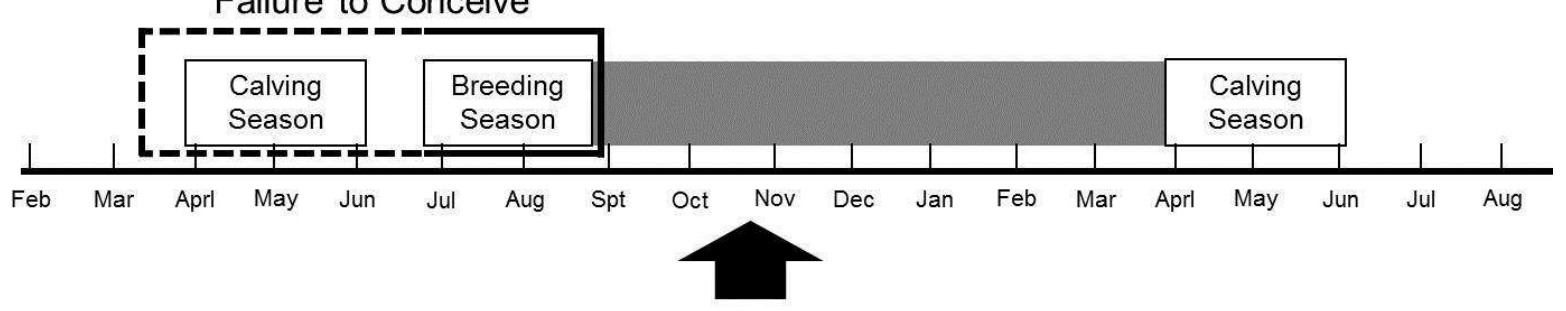

\section{Preg Check}




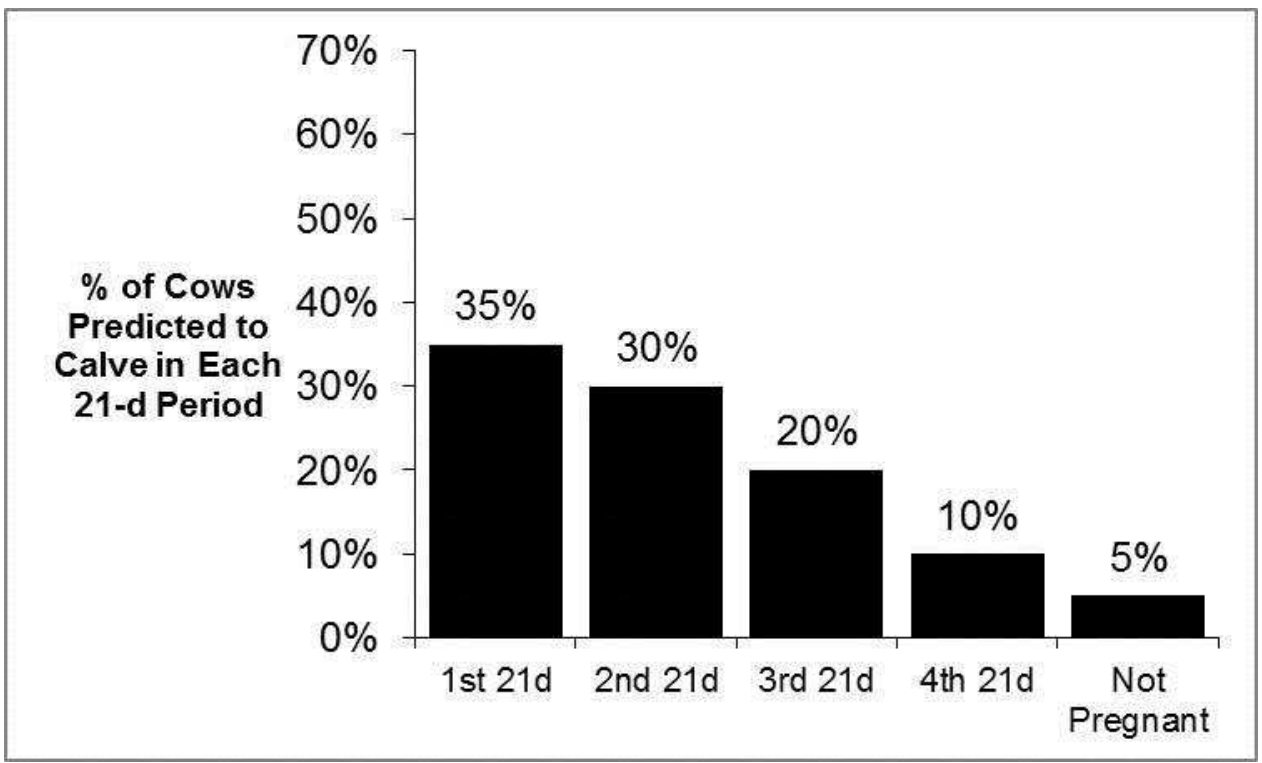




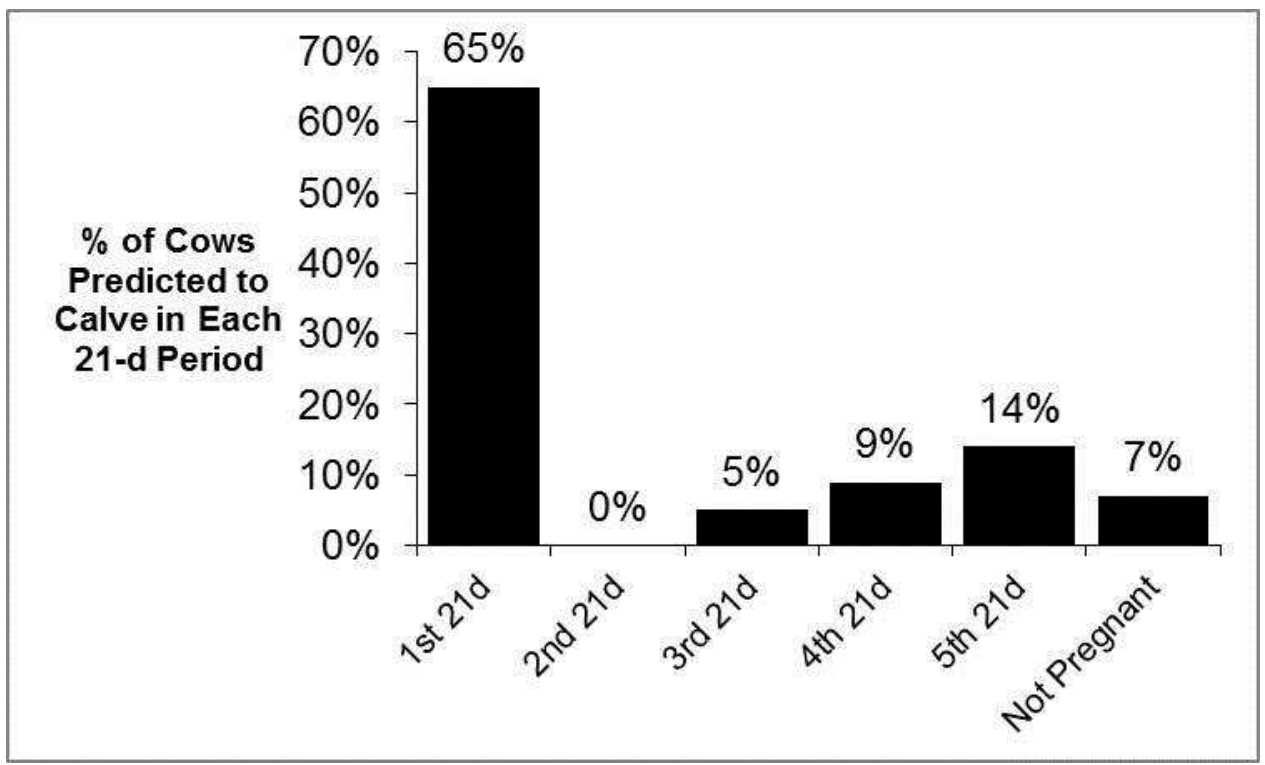




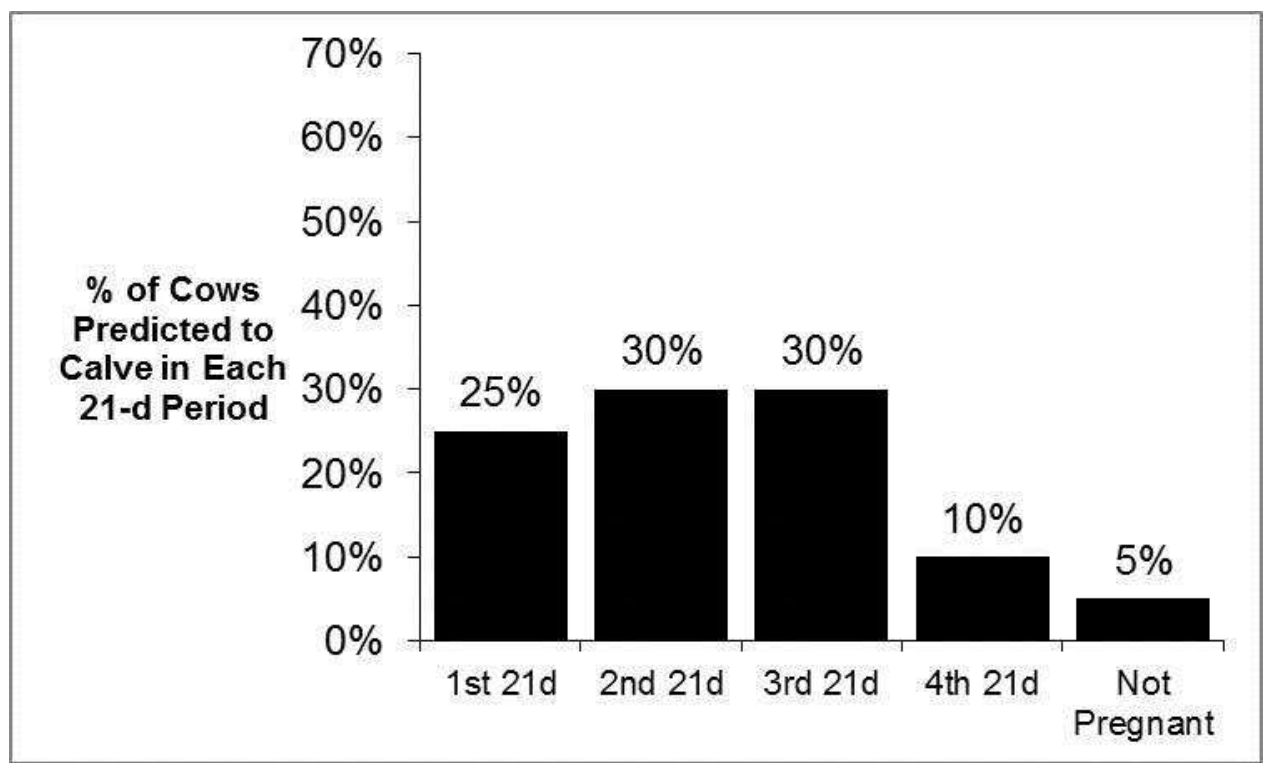




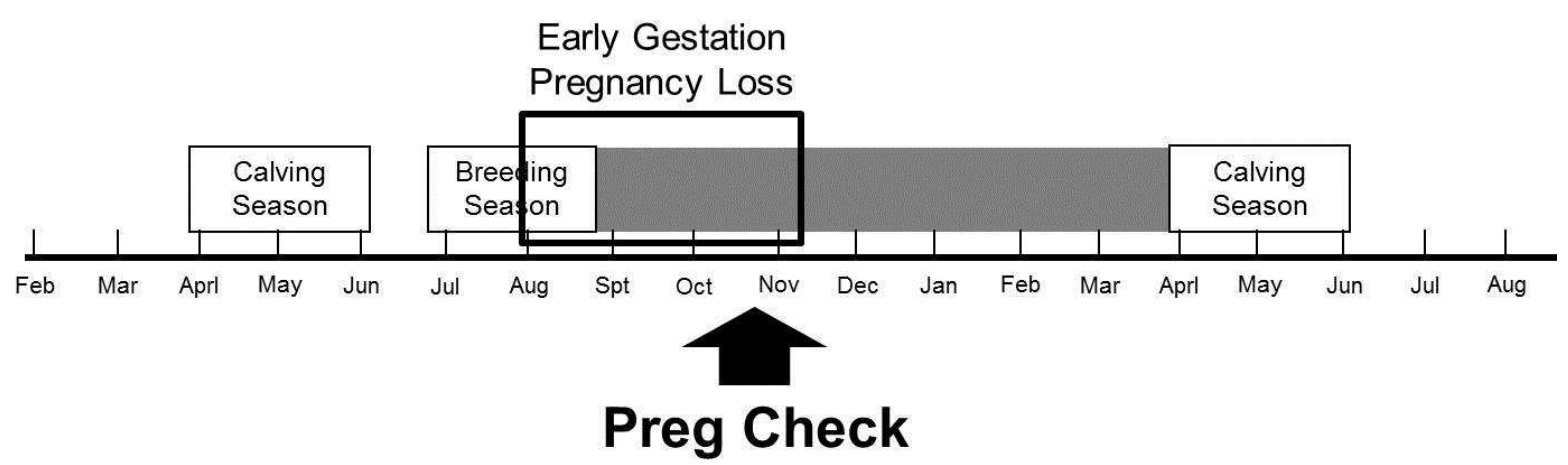




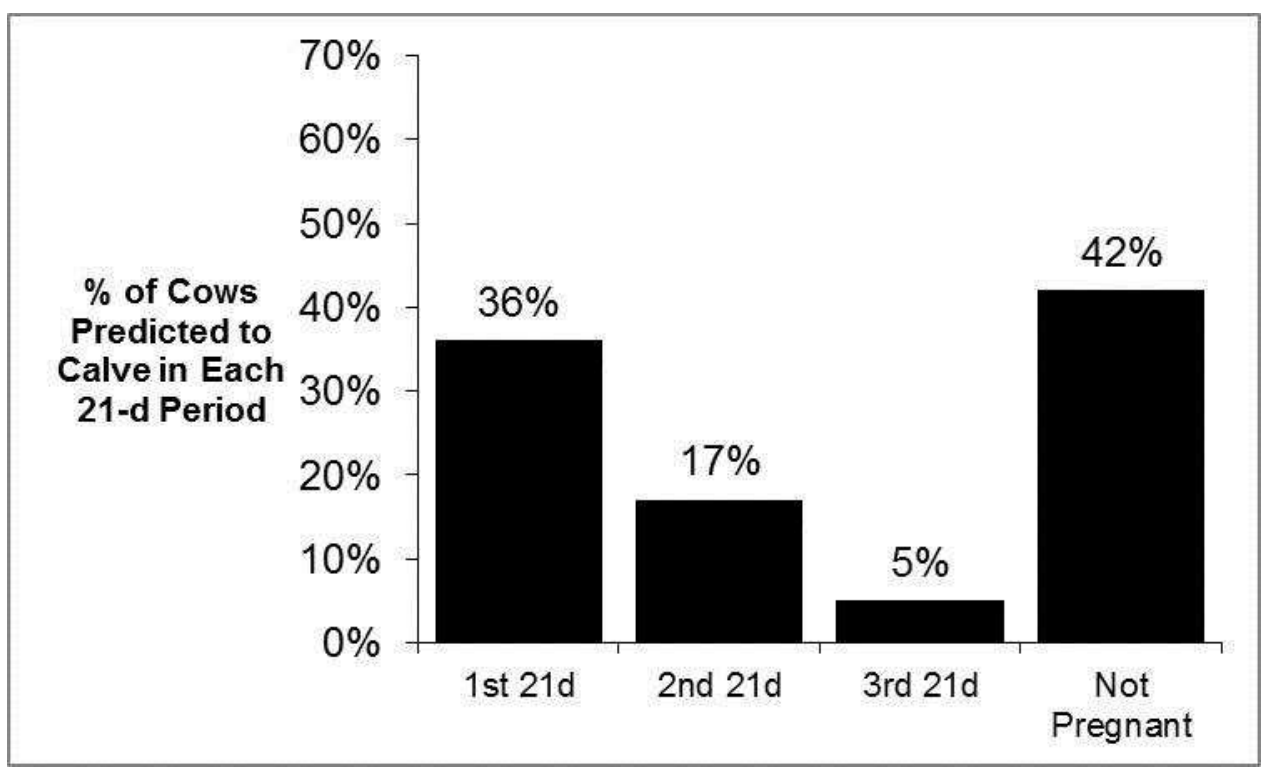




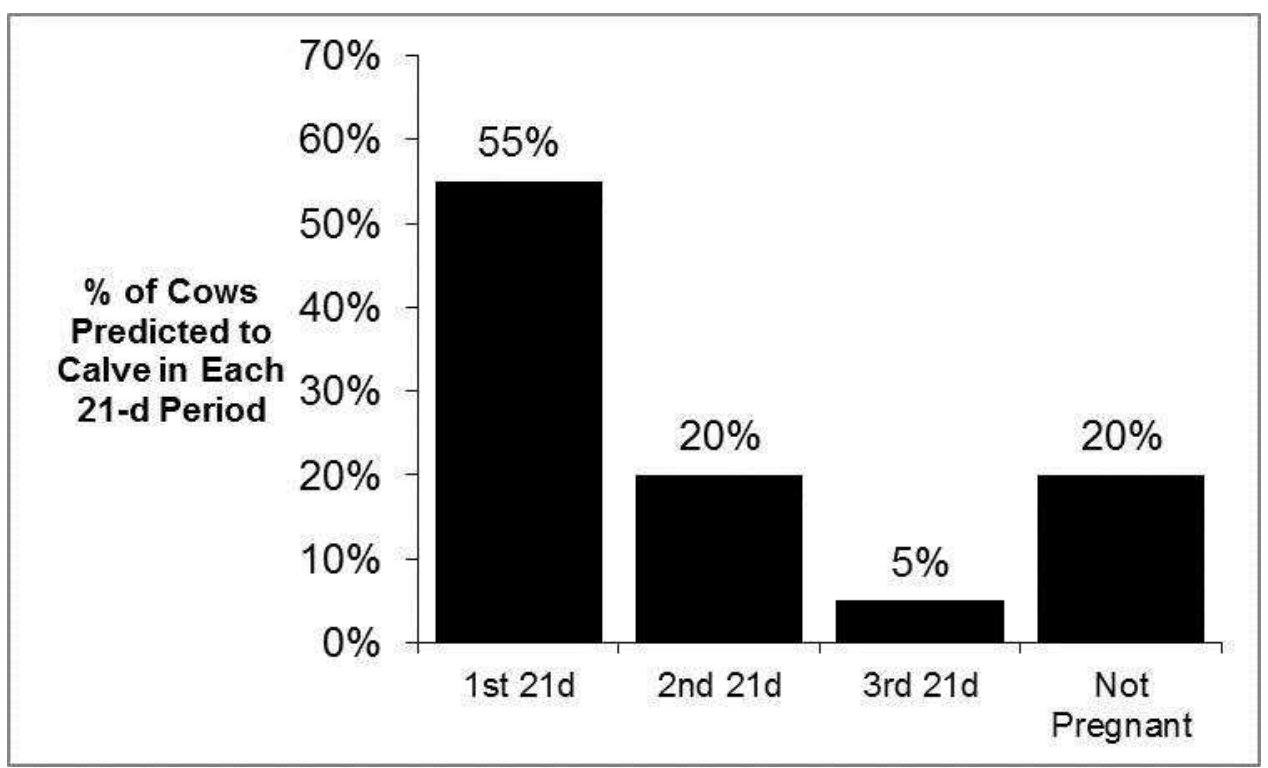


Late Gestation

Pregnancy Loss

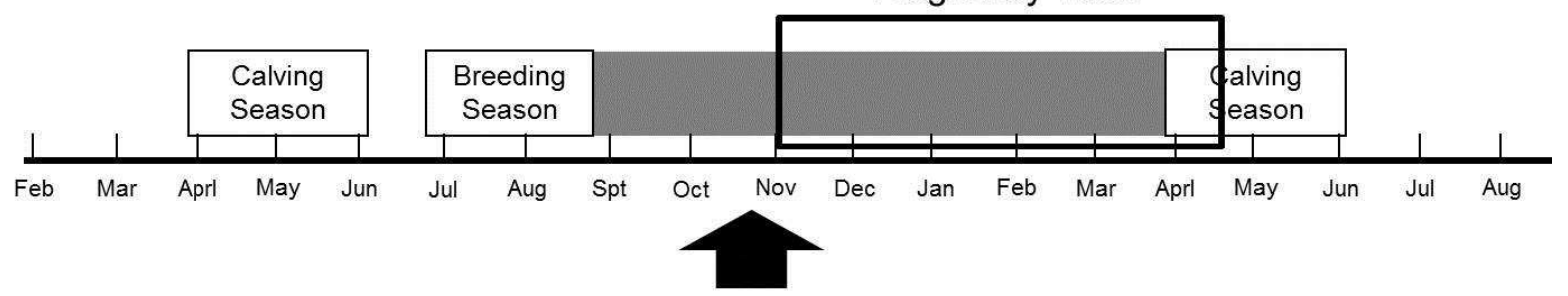

Preg Check 
Stillbirth

Loss

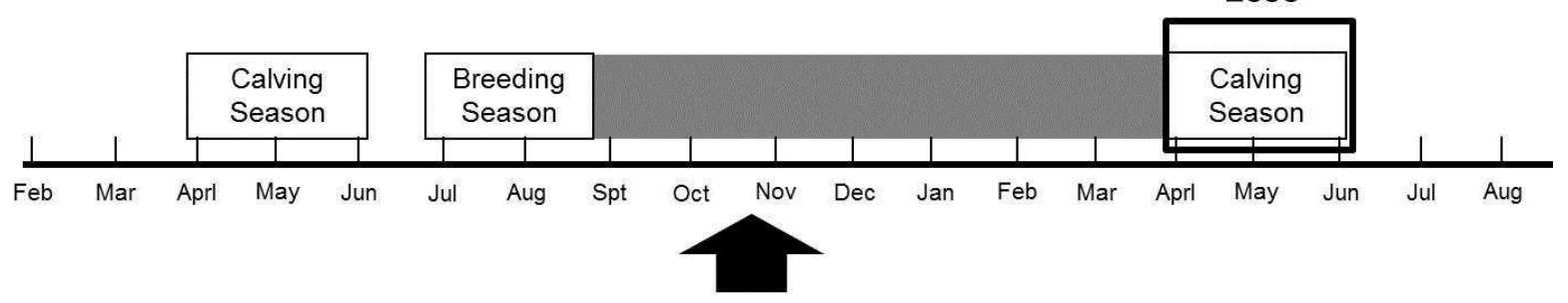

Preg Check 


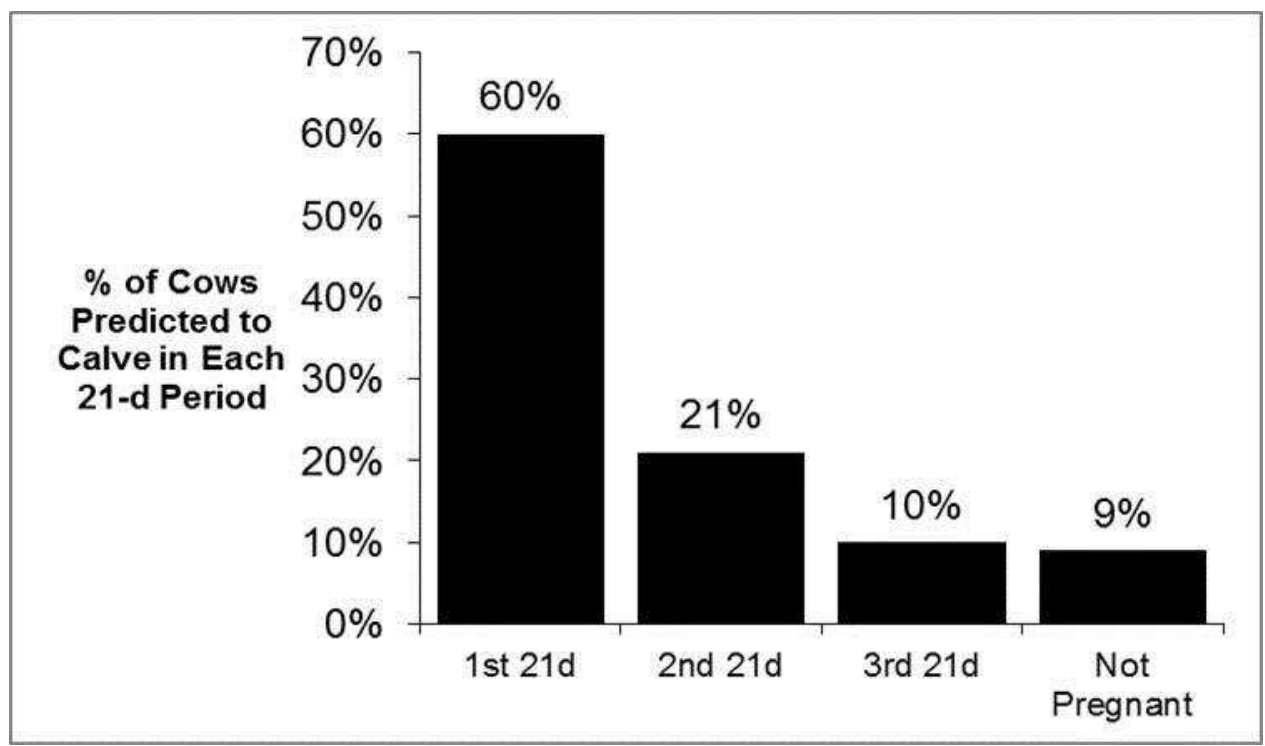




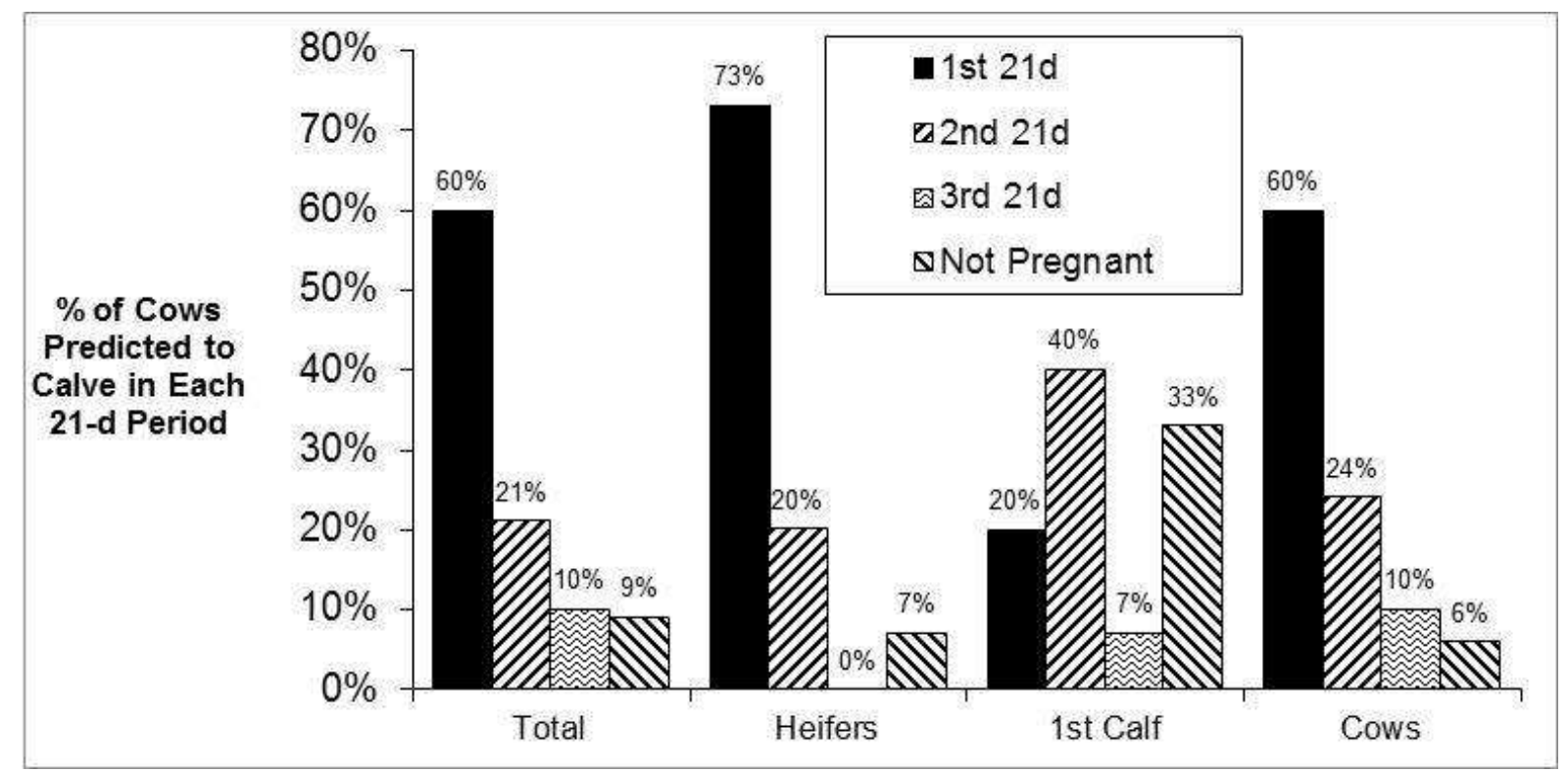

